Article

\title{
Education and Energy Intensity: Simple Economic Modelling and Preliminary Empirical Results
}

\author{
Tiago Sequeira * (D) and Marcelo Santos * (1) \\ Universidade da Beira Interior and CEFAGE-UBI, Avenida Marques d'Avila e Bolama, \\ 6201-001 Covilhã, Portugal \\ * Correspondence: tnsequeira@gmail.com or sequeira@ubi.pt (T.S.); marcelomars@hotmail.com (M.S.)
}

Received: 11 June 2018; Accepted: 24 July 2018; Published: 26 July 2018

\begin{abstract}
The ratio of energy use to Gross Domestic Product (defined as energy intensity) is a major determinant of environmental hazard and an indicator of eco-efficiency. This paper explains why education can have an effect in reducing the energy intensity thus affecting eco-efficiency. We devise a stylized economic model with simple and widely accepted assumptions that highlights the role of education in decreasing energy intensity worldwide. In an empirical application that is robust to the features of the data, we show that primary schooling contributes to a decrease in energy intensity which has a very significant effect, even accounting for the other well-known determinants of energy intensity. Additionally, when schooling is taken into account, income is no longer a negative determinant of energy intensity.
\end{abstract}

Keywords: energy intensity; income; education; eco-efficiency; circular economy

JEL Classification: Q43; O17; O50

\section{Introduction}

The evolution of energy intensity (the ratio of energy consumption to Gross Domestic Product (GDP) — as an indicator of eco-efficiency) — across the world has been established as one of the facts that is related to energy and economics (see [1]). In fact, the energy intensity has been found to be declining in time and negatively correlated with per capita output. This seems to indicate that as countries get richer, energy intensity decreases. One possible explanation for this relationship is that the gains in efficiency associated with economic growth improve the way the humankind uses energy, i.e., using it more efficiently. Thus if this interpretation is accepted, the decline in energy intensity should occur simultaneous with economic growth, both as result of technological progress. Alternatively, the reduction in energy intensity has also been associated with the structural transformation of the economy. As the economy becomes more service-intensive and less industry-intensive, energy intensity tends to be reduced (see e.g., reference [2-4]). However, [5] noted that the service sector has not been very energy efficient when analyzed by a panel of countries. More recently, reference [6] pointed out the role of financial markets in the reduction of energy intensity. In particular, the author noted that energy consumption increases generally with income per capita, except for highly advanced economies with highly developed financial markets.

It is worth noting that whatever the cause that makes energy intensity decrease with economic growth, this stylized fact clearly contributes to the establishment of a circular economy, as it is a result of the introduction of more sustainable practices in societies.

Despite several attempts to include environmental education within the school syllabus since primary education (see e.g., reference [7]), the general roles of human capital, education and schooling in decreasing energy intensity have not been studied. 
There have been very recent micro and case studies about environmental and climate change awareness of students in response to the environmental topics included in syllabus which is clear evidence of the rising interest of the topic. Reference [8] provides a description of the environmental education of elementary school students in Da Nang city, Vietnam and concludes, among other things, that students' environmental awareness improves after environmental education activities. Reference [9] studied students' environmental awareness in some elementary schools in Zonguldak, Turkey. Reference [10] analysed students awareness in high schools in Taiwan. In this study, generally, students were relatively familiar with topics taught in schools and had a positive attitude related to energy saving. Moreover, students with more educated parents tend to have significantly better knowledge than others. This may be an indication of the importance of home-taken practices and home education regarding environmental issues. Reference [11,12] studied the behaviour of secondary and elementary students, respectively, in Greece. Both revealed the importance of education in environmental awareness and in implementing energy saving and environmental friendly practices. Finally, reference [13] argues that schools must build upon up-to-date curricula and classroom activities based on cutting-edge knowledge on what drives human learning in order to increase students' environmental awareness. The acceptance of renewable energies by communities is a related topic, but within that topic, the importance of schooling has not been mentioned by the literature (for surveys on this literature that support this claim please see reference $[14,15])$. In this paper, we use the concepts of human capital, education and schooling in an inter-exchangeable manner while we recognize their different scopes and measures. While human capital includes both education and in-work experience and both can have effects in decreasing energy intensity, we really focus on the concept of education in the model, as the families choose between consumption and education (of the offsprings). Then, in the empirical application, we use schooling as it is the variable with the most available data. We leave the study of other aspects of human capital in energy intensity and eco-efficiency for further research.

We have not found studies with particular concern about the relationship between education and energy intensity at the country level. We intend to fill this gap. First, we offer an explanation based on quite intuitive and widely accepted assumptions: (i) there is a minimum subsistence level of consumption; (ii) families choose between consumption and education; and (iii) more knowledge reduces energy intensity, which can be explained both from the supply or/and the demand side of the economy.

Second, energy intensity has been analysed essentially in country or region-specific studies and with a limited data range. The methods used were almost descriptive or, at most, applied some basic econometric tools such as Ordinary Least Squares (OLS). We aim to broaden the study of the determinants of energy intensity to a large panel of data from countries, focusing on the effect of schooling. To that end, we include variables which were typically associated with energy intensity: income per capita, the industry share in the economy, energy dependence, and we also take convergence in energy intensity into account. We obtain a very strong significantly negative effect of schooling in decreasing energy intensity, supporting our presented theory. In fact, we postulate that a more educated population not only learns how to improve energy use and then to decrease its intensity in economic activities, but also becomes more aware of issues such as global warming and pollution problems and thus uses energy more efficiently. Besides that, when schooling is not taken into account, the per capita income has a strong negative effect but only in the short run, and external dependence has only a marginal negative effect on energy intensity, also in the short run. Thus, this is the first paper highlighting the role of education in reducing energy intensity and substituting the role of income per capita but maintaining the significance of all the other major determinants of energy intensity.

This paper has clear policy implications as the influence of education in energy use should be taken into account when designing education policy. Furthermore, the influence of education in energy intensity is also informative for environmental policy, as this can rely more on the educational system to achieve environmental goals. 
The remainder of the paper is organized as follows. Section 2 presents a simple model that highlights why education can have a negative effect on energy intensity and thus presents education as a potential alternative determinant of the decreasing path of energy intensity. Section 3 describes the data features, the econometric specification and the methodology. This section also highlights the features of the econometric approach that deals correctly with the main data features. Section 4 presents the empirical results. In this section, we present tests of the estimation goodness-of-fit, regressions results and their analysis. Section 5 concludes the paper.

\section{Why Education May Reduce Energy Intensity?}

A simple application of a structural transformation model (such as the one of reference [16]) would explain the importance of de-industrialization in explaining energy intensity decline given that industry is more intensive in energy than services. Thus, an increase in services and decrease in industry in a given economy will directly determine the reduction in energy intensity. However, the role of human capital in reducing energy intensity is yet to be explained. In this section, we provide a simple explanation as to why schooling can reduce energy intensity, thus contributing indirectly to decreasing the hazard caused by energy intensity. This explanation is linked with very intuitive phenomena-families need a certain amount of consumption to survive; thus, the choice between consumption and human capital implies a higher growth rate of human capital (relatively to that of consumption). Human capital contributes to the evolution of knowledge and knowledge decreases energy intensity. Note that in aggregate terms, the growth rate of energy intensity is proportional to the growth rate of consumption minus the growth rate of human capital and, as a result of that, energy intensity declines.

\subsection{A Simple Model Explanation}

We devised a very simple model that shows how human capital can contribute to reducing energy efficiency and eventually to substitute the role of income, as also happens in the regressions that we show in the following section.

The agent chooses consumption and human capital, following an utility function, $U$, as follows:

$$
U=\log (c-\bar{c})+\sigma \log (h)
$$

where $c$ is consumption; $\bar{c}$ is the minimum level of consumption or the subsistence level of consumption (e.g., as in reference [17]; $h$ is the level of human capital (or education) chosen by the families; and $\sigma$ is the weight of human capital in the families' preferences. There are various reasons why we may include human capital (or education) in the families' utility function: (i) because it represents the human capital of the offspring, which is correlated with their future income (e.g., as in reference [18]); (ii) because it is correlated with family health (e.g., in reference [19]; or (iii) because the families value their own or the offspring's knowledge (as in references [20] and [21]. We use this latter approach which serves our goals without unnecessary technicalities. The economy's resource constraint is $y=c+h$, which assumes that all prices are constant and equal in this economy, which is also a simplification without loss of generality for our purposes.

Families or society stock of knowledge evolves with the use of human capital (or schooling), such that $A=B h$ (in which $A$ stands for families or society knowledge and $B$ is a constant), which is, again, a simplification that does not imply any loss of generality for our purposes. In fact, a very fruitful body of literature beginning with reference [22] has modelled knowledge accumulation as dependent on human capital employed in the technology sector (as a supply-side explanation). However, this can alternatively be the result of a demand-side explanation. One justification for this demand-side view is that the incentives for new technologies to be invented depend inversely on the skilled workers' wages, which are negatively related to human capital (see reference [23]). The lower the wages and the higher the demand for human capital, the higher the incentive to accumulate technological knowledge 
is. Regarding the adoption of cleaner technologies specifically, reference [24] confirms that "customer requirements are another important source of eco-innovations, particularly with regard to products with improved environmental performance and process innovations that increase material efficiency, and reduce energy consumption, waste and the use of dangerous substances". In fact, the demand for new technologies can be seen as being dependent on the level of human capital.

Finally, energy intensity $(E i)$ is a function of consumption and technology, such that

$$
E i=c^{\varrho} / A,
$$

where $0<\varrho<1$ represents the elasticity of energy intensity to growing per capita consumption to account for the fact that consumption positively influences energy intensity but at a decreasing rate. From Figure 1 in reference [25]'s report, we can infer a positive effect of the increase in per capita consumption on energy efficiency; thus, $\varrho$ should be positive. However, the decreasing rate may be explained by the growing demand for energy efficiency and for "clean" electricity (see the same in Figure 1 in reference [25]). The same report highlights the importance of new technologies in the falling trend of energy efficiency. There is also literature on economic growth theory in which pollution can be decreased by technological developments $([26,27])$. Reference [28] studied the importance of developing new technologies in decreasing costs and implementing more innovative and practical approaches to energy management. Additionally, reference [29] showed that the increase in energy efficiency and promotion of renewable energy consumption are the main tools to achieve the Environmental Kuznets Curve (EKC), emphasizing the negative relationship between pollution and output growth occurrence at the world level. Otherwise, the authors concluded that the relationship between greenhouse gas emissions and total production output would be monotonically positive. The EKC, which is a related concept to the relationship between energy intensity and income (but not the same), is a hump-shaped relationship between pollution and output growth that has been extensively debated in the literature-for a critical history of the concept of the EKC see, e.g., Stern (2004) [30]. An increase in families or society's stock of knowledge (including that accumulated through home or primary schooling) is important to increase energy saving awareness and can also be related to a decrease in energy intensity. This has been recognized by reference $[10,31]$.

\subsection{Solution of the Model}

The agent maximization problem yields the optimal marginal rate of substitution between consumption and human capital:

$$
\frac{1}{c-\bar{c}}=\frac{\sigma}{h}
$$

After substitution into the resource constraint, the following equations for the optimal quantities for consumption and human capital are obtained, respectively:

$$
c=\frac{y+\bar{c}}{1+\sigma} ; h=\sigma\left[\frac{y+\bar{c}}{1+\sigma}-\bar{c}\right]=\sigma\left[\frac{y-\sigma \bar{c}}{1+\sigma}\right] .
$$

From Equation (4), the relationship between the growth rates of consumption and human capital ( $g_{x}$ is the growth rate of variable $x$ ) with the output growth rate is given as follows:

$$
g_{c}=g_{y} \frac{y}{y+\bar{c}} ; g_{h}=g_{y}\left[\frac{y}{y-\sigma \bar{c}}\right] .
$$

The following proposition highlights the main results of this stylized model.

Proposition 1. The growth rate of energy intensity is negative due to the influence of the human capital growth rate. 
Proof. From Equation (5), it is straightforward to obtain $g_{c}<g_{h}$. Then, Equation (2) is used to obtain $g_{e i}=\varrho g_{c}-g_{h}<0$, given that $0<\varrho<1$.

This means that a very stylized model which considers that (i) there is a minimum level of subsistence consumption; (ii) that energy intensity depends positively on consumption and negatively on knowledge (the model can encompass concepts such as cleaner technologies or families awareness); and (iii) that knowledge depend positively on education investments by families (e.g., in schooling) explains that energy intensity should decline and that this fall should depend crucially on education or schooling. While assumptions (i) and (iii) are quite common in economics literature, assumption (ii) relies on recent evidence on energy intensity trends. To sum up, in aggregate terms, the growth rate of energy intensity depends (positively) on the difference between the growth rate of consumption and the growth rate of human capital and, as a result of that, energy intensity declines.

\section{Empirical Application}

\subsection{Variables and Sources}

We used data from the Cross-National Time Series (CNTS) Data Archive (2015 edition), also known as Databanks International [32], to collect the variables for this article. The dependent variable was energy intensity (energy consumption per unit of GDP). Our variable of interest is schooling measured by the enrolment of primary schooling students as a percentage of the total population. This was chosen as it is the most general level of education and should proxy the investment that each society is making in educating its population towards environmental awareness. For the first time in the literature that aims to explain energy intensity, we considered an education variable as a possible explanatory variable.

As other explanatory control variables, we used the other determinants of energy intensity which have been mentioned in the literature. Each of them are defined below with an explanation of the reason for them to be included in our analysis:

- Income per capita (Gross Domestic Product per capita (factor cost)). We chose to use GDP per capita at factor costs as this excludes the influence of taxation (and subsidization) in the economy (which GDP at market prices would include). Most articles that explain energy intensity at the country level (such as reference [2,4]) use income per capita as an explanatory variable.

- Percentage of GDP originating in industrial activity (or industrial share in GDP). Some papers have analysed the effect of some sectors' shares in the economy (e.g., reference [4]) or an industry dummy (e.g., reference [3]) as determinants of energy intensity. To deal with this issue, reference [5] studied energy intensity only in the services sector. Although reference [2] ignored this variable, reference [33] exhaustively explored the relationship between industry share and energy intensity.

- External energy dependence (energy consumption minus energy production). This variable was introduced to proxy price shocks. Prices is also a common variable to enter in regressions in country-specific studies, as in reference [2] or [4]. However, as a substitution variable for the price of energy comparable between different countries, which we could not obtain, we used external energy dependence. As reference [34] stated, "by energy dependence, we mean the vulnerability of a given Member State to energy price shocks or energy supply disruptions".

Table 1 presents the descriptive statistics for the variables. 
Table 1. Descriptive Statistics.

\begin{tabular}{lccccc}
\hline Variable & Observations & Mean & Std. Dev. & Min & Max \\
\hline Energy Intensity & 7322 & 0.801 & 1.078 & 0.006 & 17.679 \\
GDP per capita & 9503 & 4538.516 & 10622.56 & 18 & 186,243 \\
Share of Industry & 5393 & 27.556 & 14.160 & 0 & 96 \\
External Energy Dependency & 6949 & -2980.458 & $63,021.74$ & $-618,978$ & 641,541 \\
Primary Schooling & 12,552 & 0.1134 & 0.0556 & 0.0001 & 0.4943 \\
\hline
\end{tabular}

Notes: Energy intensity is measured as energy consumption per unit of GDP; GDP per capita is at factor costs (units of US dollars); the share of industry is the ratio of the industrial output to GDP; the external energy dependency is a trade balance of energy (energy consumption minus energy production); primary schooling is the enrolment of students in primary schools per capita. The presented statistics were calculated for the following number of observations.

\subsection{Cross-Country Dependency and Non-Stationarity}

The non-stationarity of macroeconomic variables is a well-known feature that has concerned macro-economists, namely after reference [35]'s contribution. More recently, reference [36], for instance, concluded that real GDP and GDP per capita are non-stationary. Additionally, variables linked with energy (namely energy consumption) also share the same property (see e.g., [1]). This means that an empirical approach that relates macroeconomic variables in the long-run to any other macroeconomic variable (in particular, energy intensity) must account for the potential non-stationarity of the series. Our approach is robust to the presence of non-stationarity in the series-see reference [37] for the advantages of using the common correlated heterogeneous panel data estimator to deal with the common features of macroeconomic series in large panels of data.

Additionally, income growth, energy intensity decline and structural transformation are worldwide phenomena and are obviously correlated among different countries. International technological shocks (such as the introduction of electricity or the computer on production) or financial shocks (such as the sub-prime crisis) are often considered to be the sources of cross-correlation of GDP per capita. We have historically observed that these shocks are contagious to various neighbour countries and usually entire regions or even the global economy. Moreover, it is natural to think that energy intensity is cross-country correlated, as it depends mostly on technological advances that allow for more efficient methods and to the general development of the world, which includes the spread of ideas, such as environmental protection and the dangers of global warming. The results of reference [38]'s test for cross-country dependence for the three main variables are presented in Table 2, and they clearly show that the three variables are highly cross-country correlated. The other variables that enter into the analysis—schooling and external energy dependence-do not have sufficient observations to perform this test. Despite the fact that there are reasons to believe that these variables are also cross-country dependent, we do not need all the variables to be cross-country dependent to ensure the validity of the application of the common correlated heterogeneous panel data estimator.

Table 2. Cross-Section Dependence.

\begin{tabular}{lccc}
\hline Variable & Cross-Dependence (CD) Test & $\boldsymbol{p}$-Value & Countries \\
\hline Energy intensity & 307.89 & 0.000 & 114 \\
GDP per capita & 547.61 & 0.000 & 156 \\
Industry share & 75.85 & 0.000 & 81 \\
\hline
\end{tabular}

Notes: The average number of time-series observations is 42.00 for the first test and 45.17 for the second and 38.16 for the third.

As reference [37] observed, "the standard empirical estimators (e.g., fixed effects, difference and system Generalized Method of Moments (GMM)) not only impose homogeneous production technology, but they also implicitly assume stationarity, cross-sectionally independent variables". 
The fact that some of our variables (namely, the dependent variable, energy intensity) are non-stationary implies that the usual stationarity error term assumption would be violated.

In the presence of cross-country dependence, individual countries cannot be viewed as independent cross-sections, and consequently, cross-section dependence can affect both inference and identification (see $[37,39])$. This literature argues that cross-country dependence implies that standard panel data estimators are inefficient, and estimated standard errors are biased and inconsistent. Generally, inconsistency arises as an omitted variable bias when the observed explanatory variables are correlated with the unobserved common factors (see, e.g., reference [40]), such as the shocks mentioned above. Due to both potential non-stationarity and cross-country correlations, traditional methods may not be useful for evaluating the effect of income per capita, industry share, external energy dependence, or primary schooling on energy intensity. As a result, we used the [40] common correlated effects mean group estimator-augmented to be robust to reverse causality-to access this empirical relationship. Along the same line, reference [37] argues that this class of heterogeneous estimators is superior to traditional fixed-effects and instrumental variable panel estimators in macroeconomic applications. A similar econometric approach to explain the relationship between country-risk and energy supply was followed in reference [41].

\subsection{Specification and Methods}

Granger causality is an important issue when evaluating any economic relationship, because it means that an economic series is useful for predicting the behaviour of another series. In this case, it is useful for the determination of whether schooling is important to the prediction of energy intensity (in the Granger sense). This also applies to the relationship between energy use, income, energy dependency, structural transformation and schooling. To that end, we estimated our model using an error-correction model (ECM) approach. This method distinguishes between long run effects and short run effects of the explanatory variables on the energy intensity. According to the econometrics literature cited above, this estimator is robust to (i) country-fixed effects, such as geography and culture or initial technology or natural resources endowment levels; and (ii) unobservable common variables, such as common productivity change or global energy market conditions, which are important factors in this empirical application. In fact, the large time-series that we incorporated into our empirical application allowed us to implement the ECM which offered the following advantages when compared to other approaches: (i) it distinguishes between the short and long run effects of explanatory variables on energy intensity; (ii) the error-correction term can be investigated to determine the speed of energy use adjustment; and (iii) cointegration can be tested in the ECM by closer investigation of the statistical significance of the error-correction term.

The equation for a baseline model to explain energy intensity could be written as follows:

$$
E_{i t}=\delta_{1 i} E_{i t-1}+\delta_{2 i} y_{i t}+\delta_{3 i} i_{n d}+\delta_{4 i} n e i_{i t}+\delta_{5 i} \text { school }_{i t}+u_{i t} ; u_{i t}=\alpha_{i}+\lambda_{i}^{\prime} \mathbf{f}_{t}+\varepsilon_{i t},
$$

where $E_{i t}$ is the energy intensity; school is the enrolment in primary school, our variable of interest; $y_{i t}$ is the GDP per capita; $i n d_{i t}$ is the industry share in the economy; and nei $i_{i t}$ is the net energy imported (or energy dependence); $\delta_{1 i}-\delta_{5 i}$ are the coefficients that measure the (heterogeneous) influence of each of the explanatory variable in energy intensity. The error-correction model version of Equation (6) can be written as follows:

$$
\begin{array}{r}
\Delta E_{i t}=\alpha_{i}+\rho_{i}\left(\beta_{1 i} E_{i t-1}-\beta_{2 i} y_{i t-1}-\beta_{3 i} i n d_{i t-1}-\beta_{4 i} n e i_{i t-1}-\beta_{5 i} \text { school }_{i t-1}-\lambda_{i}^{\prime} \mathbf{f}_{t-1}\right) \\
+\gamma_{1 i} \Delta y_{i t}+\gamma_{2 i} \Delta \operatorname{sind}_{i t}+\gamma_{3 i} \Delta n e i_{i t}+\gamma_{4 i} \Delta \text { school }_{i t}+\gamma_{i} \Delta \mathbf{f}_{t}+v_{i t},
\end{array}
$$

where $\beta_{j i}$ stands for the long run equilibrium relationship between energy intensity, income, schooling and the other covariates, and $\gamma_{j i}$ stands for the short run relationship between those variables. With $\beta_{5 i}=\gamma_{4 i}=0$, we would have the ECM version without schooling, a version whose results we will also present to compare with our baseline one. The factor $\mathbf{f}_{t}$ represents the common factors 
that influence the evolution of energy intensity, GDP, industrial share (or structural transformation) and schooling in different countries, such as technological, political, educational and energy supply shocks. Although these factors are common to all countries, their influences in each country can be different as $\lambda_{i}$ and $\gamma_{i}$ are country-specific coefficients. Along these lines, the model incorporates the full heterogeneous effects of GDP, structural transformation and schooling on the energy intensity across countries. The estimated equation can thus be re-written as

$$
\begin{gathered}
\Delta E_{i t}=\pi_{0 i}+\pi_{1 i} E_{i t-1}+\pi_{2 i} y_{i t-1}+\pi_{3 i} i_{i n d} d_{i t-1}+\pi_{4 i} n e i_{i t-1}+\pi_{5 i} s \text { school }_{i t-1}+\pi_{F i}^{\prime} \mathbf{f}_{t-1}+ \\
+\pi_{6 i} \Delta y_{i t}+\pi_{7 i} \Delta i n d_{i t}+\pi_{8 i} \Delta n e i_{i t}+\pi_{9 i} \Delta \text { school }_{i t}+\pi_{f i}^{\prime} \Delta \mathbf{f}_{t}+v_{i t}
\end{gathered}
$$

where $\pi_{1 i}=\rho_{i}$.

From the regression results, the long run coefficients, $\beta_{j i}$, in (8) can be obtained dividing the estimated coefficients from Equation (9), $\pi_{j i}$ by $\rho_{i}\left(\beta_{j i}=-\frac{\pi_{j i}}{\rho_{i}}\right)$, which is the speed of convergence of the energy intensity to its long run equilibrium. Inference on the coefficient for the lagged energy intensity will indicate the presence of a long run equilibrium relationship. If $\rho_{i}=0$, there will be no error correction and the model will reduce to a regression with variables in the first-differences (the level term in brackets in Equation (8) disappears). However, if $\rho_{i} \neq 0$, we observe error-correction, meaning that following a shock, the economy returns to its energy intensity long run equilibrium path and thus, cointegration exists between the variables and processes in brackets (in Equation (8)). As noted above, we also estimated a restricted model with $\pi_{5 i}=\pi_{9 i}=0$, i.e., without school in the regression.

In accordance with the econometric literature $([40,42])$, we added cross-section averages of all variables in the model (energy intensity, GDP per capita, industry share and primary school enrolment) to Equation (9). This procedure replaces the unobservable and omitted elements of the cointegration relationship. However, reference [43] showed that this approach may suffer from a small sample bias, especially in panels with time-series of moderate dimensions. Thus, they offered a strategy to deal with weakly exogenous regressors which is robust to reverse feedback. As argued by the mentioned authors, the inclusion of lags will strengthen the estimations to reverse causality, meaning that the estimated coefficients may be regarded as measuring the effect of schooling (and of the other explanatory variables) on energy intensity and not the other way around. In fact, the study of a potential effect of energy intensity on schooling is beyond the scope of this article. However, the effect of energy consumption (related to energy intensity) has been study by others (e.g., reference [44]) and is also beyond the scope of this study. We followed their suggestion including further lags of the cross-section averages mentioned above.

$$
\sum_{l=1}^{p} \tau_{1 i l} \overline{\Delta y}_{t-p}+\sum_{l=1}^{p} \tau_{2 i l} \overline{\Delta i n d}_{t-p}+\sum_{l=1}^{p} \tau_{3 i l} \overline{\Delta n e i}_{t-p}+\sum_{l=1}^{p} \tau_{4 i l} \overline{\Delta s c h o o l}_{t-p}+\sum_{l=1}^{p} \tau_{5 i l} \overline{\Delta E}_{t-p} .
$$

In particular, we followed the rule of thumb in that reference ([43]) to choose the number of lags to be included $\left(p=T^{1 / 3}\right)$. In a time-series of near 40 years on average, that rule of thumb indicated a value between 3 and 4 . In ECM, this corresponds to adding two or three lagged differences. We chose to include three lagged differences.

\section{Results}

We estimated Equation (9) and show the results in Table A1. Columns (1) and (2) show the model specification without schooling and column (3) shows the model specification with primary schooling as an explanatory variable.

\subsection{Estimation Quality Tests and Evidence}

We estimated regressions from a large panel database with more than 1200 observations and an average of more than 30 time-series observations for nearly 40 countries. In general, data included 
in regressions began in 1950 and ended in 2009, although this varied across countries as is natural for an unbalanced panel. In the Appendix, we include a list of the countries that were used in the analysis with information about their respective time spans. Note that due to the availability of data, the database is mostly composed of developed and developing countries, including very few poor countries. This is the largest database ever reported in the literature-in both time-series and cross-section dimensions- to approach the determinants of energy intensity. There was evidence of error-correction. The lagged energy intensity variable was highly statistically significant and negative with an implied half-life - an indicator of the speed of adjustment of energy intensity following a shock, computed as $\ln (0.5) / \ln \left(1+\pi_{1 i}\right)$ —o 1 year and 7 months. In any event, these are very fast speeds of adjustment for the energy intensity. Thus, this study confirms the high convergence of energy intensity found in the literature using other methods (e.g., in reference [2]). In the table, we present diagnostic tests related to stationarity and cross-section dependence, the issues for which the used method is particularly robust. The Stat-test (res) rejected the unit-root null hypothesis for the error term which indicates that the econometric approach corrected for the non-stationarity found in data, as expected. Concerning the cross-correlation of the error term, we present the CD-test (res). From the analysis of the results, we can say that all the residuals presented less evidence of cross-sectional correlation than the dependent variable did (compare with the results in Table 2), in line with what has been argued by, e.g., reference [45]. Notably, in the regression of column (3) with schooling included, the test did not reject the null of no cross-sectional dependence, suggesting that in this case, the method completelly corrected for cross-sectional dependence. Finally, the Wald test indicated the overall significance of the regressions.

An important (and not so common) feature of these estimations is that there was a high number of observations per country but not much oscillation between them (the minimum number of observations per country was 26 or 31 depending on the regression, and the average was 32 or 33, respectively. This feature of the data is important as it deals with the point raised by reference [46] which argued that the estimator in reference [40] is adequate for panel databases with a large-T dimension, in order to avoid the small sample bias. Also, reference [43] showed that the cross-sectionally averaged augmented common correlated effects (CCE) estimator (used in the estimations in Table A1) performs quite well in the presence of heterogeneous coefficients, weakly exogenous regressors and persistent factors, but can be affected by the time-series bias if $\mathrm{T}$ is small. Additionally, references $[43,46]$ argued that the bias affecting regressors (in our case, GDP per capita, schooling and industry share) other than the lagged dependent variable (in our case the lagged energy intensity) is just a proportion of the bias affecting the lagged dependent variable. Applying these arguments to our empirical application and given a quite large T-dimension in our database, we argue that the coefficients on income, schooling, industrial share and energy dependence should not be affected (much) by the time-series bias.

\subsection{Interpretation of the Regression Results}

When primary schooling was considered (column 3), there were long run negative effects of primary schooling (on energy intensity), industrial share (positive on energy intensity), and external energy dependence (negative on energy intensity). We tested the same regressions by substituting primary schooling by secondary and tertiary schooling (from the same source of data) and these two last variables were revealed to be not statistically significant-see the results in the Appendix. In the light of the discussion of the effect of schooling in environmental awareness which we made in the Introduction, there is not a consensus on the micro and case studies for which of the level of education is more important. Thus, our contribution highlights primary schooling to be the most important. We thank a referee for calling our attention to this issue. A short run positive effect of energy external dependence also appeared in this regression. Quantitatively, a one percentage point increase in primary school enrollment reduced the energy intensity by $0.05 \%$ of the GDP per capita. A one percentage point increase in primary school enrolments is completely feasible in the process of development of a country. Looking at Table 1 , the standard deviation for primary school enrolments is nearly 5 percentage points, meaning that just a one standard deviation increase in primary schooling enrolment would decrease 
the energy intensity by $0.25 \%$ of the GDP per capita. For example, India grew by nearly 8 percentage points in primary school enrolments just between 2000 and 2008. When looking at the values of Table 1 , one could observe that the energy intensity ranges from $0.6 \%$ of GDP (minimum) and has an average of $80 \%$ of GDP. This means that an average country, that in one year grew roughly 1 standard deviation in primary school enrolment per capita, decreased from $80 \%$ of GDP (taking the mean as the initial point) to $79.75 \%$. In 8 years, this should amount to nearly $78 \%$. In 30 years, this means that a country could decrease its energy dependency to $72.5 \%$, representing almost $10 \%$ of the initial value. If a country departs from an initial value of $20 \%$ of energy intensity, a decrease of $8.5 \%$ represents almost halving the initial value, which can only be regarded as a quantitative meaningful effect-and this could be obtained just with the effect of schooling. In the following paragraph, we analyse the quantitative effects of other variables.

An increase of one percentage point in the share of industry contributed to an increase in energy intensity of $1.8 \%$ of the GDP per capita which is a very important effect when we recall that energy intensity ranges from $0.6 \%$ of GDP (minimum) and has an average of $80 \%$ of GDP. Finally, a 1 USD increase in energy dependency decreased the energy intensity by $0.001 \%$ of GDP per capita in the long run and increased it by $0.001 \%$ in the short run. Again, looking at Table 1, the standard deviation of energy dependency was 63021 USD; thus, a standard deviation increase in external dependency would decrease energy intensity by $63.02 \%$ of GDP per capita in the long run and increase it by $63.02 \%$ in the short run, which is undoubtfully a high quantitative effect.

Interestingly, in this regression, the income variable was not statistically significant in explaining the decline in energy intensity, in the short, nor the long run, which was a common result in previous empirical work on energy intensity. This may indicate that schooling tends to substitute income in explaining the decline in energy intensity.

Because of that and to better assess the effect of schooling in explaining energy intensity, we wanted to compare the results with the models in which we excluded schooling from the set of regressors (columns (1) and (2)). While in the case presented in column (1), we used all the available data after excluding schooling, in column (2), we fixed the same database that was used in the baseline regression in column (3) so that, in this case, differences in results were not dependent on differences in the database.

In the regression presented in column (1), a 1 unit increase in income per capita variations decreased the energy intensity by $0.07 \%$ of GDP per capita in the short run. However, an increase in the net energy dependence variation of 1 USD would increase energy intensity by $0.003 \%$ of GDP per capita in the short run. Thus, in this regression, only statistically significant results were shown in the short run. In column (2), also without schooling, but with the same sample as in the regression with schooling, all results were maintained (here, a 1 unit increase in income per capita variations decreased energy intensity by $0.05 \%$ of GDP per capita in the short run), but there was an additional statistically significant result - external energy dependence also decreased the energy intensity in the long run by $0.002 \%$ of GDP per capita.

When comparing one regression to another, it seems that primary schooling and deindustrialization are the most important explanations for the decline in energy intensity in the long run after the second half of the 20th century, while the external energy imbalance seems to have been the most influential variable both in the long and in the short run, working to decrease energy intensity in the long run but increasing it in the short-run.

The effect of schooling as a substitution for income as a (negative) determinant of energy efficiency was not determined by the different samples in the regressions. In fact, column (2) shows a relationship that does not include schooling but maintains the smaller sample. This confirms that the negative effect of income on energy intensity vanishes when schooling is introduced, even when exactly the same sample is maintained. 


\section{Shortcomings, Limitations and Prospects for Future Research}

This study presents the limitations relative to the single econometric method and the dataset that were used. However, we think that the method used was quite appropriate to the nature of data (see, again, reference [37]), as it is robust to non-stationarity, cross-dependency and heterogeneous effects. Additionally, the method also accounts for the omitted variable bias and reverse causality due to common factors but has heterogeneous effects inside different countries-all important issues that affect macroeconomic data in general and in our dataset in particular. In fact, causality was approached with the error-correction method and by the introduction of lags of the explanatory variables, which is the general approach for dealing with causality in econometrics (e.g., in other dynamic or system GMM panel estimators, as initiated by reference [47]). However, it should be noted that the method accounts for causality à la Granger (schooling helps to predict energy intensity) which does not exactly mean that schooling cause energy intensity (decreasing it). This is a problem caused by the use of secondary data and econometric methods. Future research may overcome this issue in the field of experimental economics or through the study of cases monitoring the effective causality between schooling (or education for environmental awareness) and the future behaviour of children or young adults. Studies using twins could handle this issue. In fact, as argued by reference [48], the study of twin pairs is consistent with a causal effect of lifestyle factors on important late-life outcomes, which may be the object of future work.

As argued in reference [45], non-linearities are difficult to deal with this method and in order to apply the correct methodology to address non-linearities we would need a larger database than the one used in this paper. Note that a larger database would come in the expense of dropping covariates that were already tested in econometric explanations of energy intensity which would lead to obvious omitted variable bias.

The used data came from a credible database that is widely used in macroeconomics. Additionally, after various attempts to improve coverage by concatenating different data sources, this was the one that provided the widest possible panel for the variables used. However, it had also some drawbacks. In particular, it is important to note that a reasonable proportion of the countries data ends in 1980 (see Appendix for a complete description of the countries and years covered). In fact, data ends in 1980 for 17 out of $52(33 \%)$ countries in column (1) (Table 3) and 12 out of 39 in columns (2) and (3) (31\%). To overcome this issue, country studies which using quarterly data on energy intensity and schooling may be an avenue to be pursued by future research. 
Table 3. Schooling, income and energy intensity.

\begin{tabular}{|c|c|c|c|}
\hline & $\begin{array}{c}\stackrel{(1)}{\text { Without School-Enlarged Sample }} \\
\text { W }\end{array}$ & $\begin{array}{c}\text { (2) } \\
\text { Without School-Same Sample }\end{array}$ & $\begin{array}{c}\text { (3) } \\
\text { With School }\end{array}$ \\
\hline Income per capita ${ }_{t-1}$ & $\begin{array}{c}-0.0001 \\
(0.313)\end{array}$ & $\begin{array}{c}-0.0001 \\
(0.188)\end{array}$ & $\begin{array}{c}-0.0001 \\
(0.384)\end{array}$ \\
\hline$\Delta$ Income per capita $_{t}$ & $\begin{array}{l}-0.0007 * * * \\
(0.000)\end{array}$ & $\begin{array}{l}-0.0005^{* * * *} \\
(0.000)\end{array}$ & $\begin{array}{l}-0.004 \\
(0.192)\end{array}$ \\
\hline Industry Share $_{t-1}$ & $\begin{array}{l}-0.009 \\
(0.140)\end{array}$ & $\begin{array}{l}-0.005 \\
(0.458)\end{array}$ & $\begin{array}{l}0.018^{* *} \\
(0.027)\end{array}$ \\
\hline$\Delta$ Industry Share $_{t}$ & $\begin{array}{c}0.004 \\
(0.425) \\
\end{array}$ & $\begin{array}{c}0.03 \\
(0.574) \\
\end{array}$ & $\begin{array}{c}0.015 \\
(0.236) \\
\end{array}$ \\
\hline External Dependence $_{t-1}$ & $\begin{array}{c}-0.0000 \\
(0.174)\end{array}$ & $\begin{array}{l}-0.00002 * * \\
(0.023)\end{array}$ & $\begin{array}{c}-0.0001 * \\
(0.100)\end{array}$ \\
\hline$\Delta$ External Dependence $_{t}$ & $\begin{array}{l}0.00003 * * * \\
(0.003)\end{array}$ & $\begin{array}{l}0.00003^{* *} \\
(0.010)\end{array}$ & $\begin{array}{l}0.091 * * \\
(0.034)\end{array}$ \\
\hline Primary School $_{t-1}$ & - & - & $\begin{array}{l}-0.0005^{* * *} \\
\quad(0.002)\end{array}$ \\
\hline$\Delta$ Primary School $_{t}$ & - & - & $\begin{array}{c}-0.0001 \\
(0.615) \\
\end{array}$ \\
\hline Error Correction Coefficient $E_{i t-1}$ & $\begin{array}{l}-0.353^{* * *} \\
(0.000)\end{array}$ & $\begin{array}{l}-0.355^{* * *} \\
(0.000)\end{array}$ & $\begin{array}{l}-0.350^{* * *} \\
(0.000)\end{array}$ \\
\hline N Observ. & 1631 & 1266 & 1266 \\
\hline Avr. N Obs. & 31.4 & 32.5 & 32.5 \\
\hline Min-Max & $26-35$ & $31-35$ & $31-35$ \\
\hline Number Countries & 52 & 39 & 39 \\
\hline Wald & $152.22 * * *$ & $136.85^{* * *}$ & $65.31^{* * *}$ \\
\hline CD-test (res) & $2.98^{* * *}(0.003)$ & $2.52 * *(0.012)$ & $-0.36(0.718)$ \\
\hline Stat-test (res) & rejects I(1) & rejects I(1) & rejects I(1) \\
\hline
\end{tabular}

Note: The dependent variable is energy intensity (energy consumption/GDP). Values in parentheses below the coefficients are $p$-values from robust (clustered) standard errors. The regressions include two lags of lagged differences of cross-section averages. Level of significance: ${ }^{* * *}$ for $p$-value $<0.01$; ${ }^{* *}$ for $p$-value $<0.05$; * for $p$-value $<0.1$. The Wald test is a joint significance test for the regressors. The CD-test is a Pesaran (2004) cross-section dependence test on the null value of cross-section independence done on the residuals from the regression ( $p$-value presented in parentheses). The stat-test is the [49] unit root test made on the residuals. This test used four lags and rejected I(1), which means that in all lags, the test of the unit root rejects with and without a trend. The list of countries that were used in the regressions is available upon request.

\section{Conclusions and Policy Implications}

The energy intensity (the ratio of energy use or consumption to GDP-which can also be seen as an indicator of eco-efficiency) is one of the most debated indicators that relate to development and environment protection and thus, to the creation of a circular economy. In this paper we illustrate that schooling can have an effect on decreasing energy intensity, thus improving worldwide eco-efficiency and helping to establish a circular economy. If levels of schooling prove to be effective in decreasing the intensity in the use of energy, then they are contributing to a more ecologically efficient world. The establishment of a circular economy depends crucially on the capacity to minimize the use of non-renewable resources, pollution and waste for which ecological efficiency is a necessary condition.

First, we devised a simple model that explains the effect of schooling based on the trade-off between consumption and schooling and on the influence knowledge should have in decreasing the intensity in the use of energy. In aggregate terms, the growth rate of energy intensity was shown to be dependent (positively) on the difference between the growth rate of consumption and the growth rate of human capital and, as a result of that, energy intensity declined.

In an empirical application, we used an econometric estimator that is indicated for macroeconomic large panel databases - with non-stationary data and cross-section dependence-which has recently became available in the econometrics literature to address the determinants of energy intensity, namely 
schooling. Our results presented a significantly negative long run effect of primary schooling enrollment on energy intensity. Furthermore, there was a negative influence of income on energy intensity in the short run that vanished, however, when primary schooling enrollment was included in the regression. This effect of primary schooling as a substitute for income per capita in explaining the diminishing energy intensity that has been verified around the world may be explained by the effect that this level of schooling has on the demand for new cleaner technologies that help to decrease energy intensity. At least two reasons may be attributed to be beyond the importance of primary schooling: (i) the primary schooling enrolment is a proxy for the investment a society is making on basic education, and environmental awareness belongs to the set of basic education concepts; and (ii) basic education of children, including environmental awareness, influences whole families to decrease their energy use or intensity (i.e., children influence their own families' behaviours). However, further research is needed to establish this in case or experimental studies. The satisfaction of basic consumption needs at low income levels may justify why energy intensity decreases only for higher development levels.

All in all, it seems that primary schooling and deindustrialization are the most important explanations for the decline in energy intensity in the long run after the second half of the 20th century, while the external energy imbalance seems to be the most influential variable both in the long and in the short run, working in order to decrease the energy intensity in the long run but decreasing it in the short run.

Our results highlight important policy implications. In the design of public educational policy, policy makers should be aware of this effect of primary schooling on the decrease of energy intensity, such that educational policy (targeted at primary schooling) may be seen as a substitute to public efforts to reduce the consumption of energy and to increase environmental protection. Thus, the use of revenue from taxes on energy consumption may have reinforcing effects if applied in primary schooling. Also, the primary schooling syllabus should include issues related to energy use and consumption, environmental responsible behaviour, environment protection and the danger of global warming, as these should affect future generations' behaviour towards energy use and thus, worldwide eco-efficiency and the establishment of a truly circular economy.

This paper open the prospect of further research on the empirical relationship between education and energy efficiency, substituting the focus that the literature has on the relationship with income. Analysis of this relationship, both in micro and experimental studies, may complement the evidence presented here.

Author Contributions: T.S. designed the research idea, did the literature review, developed and solved the theoretical model, analysed the results and wrote the text. M.S. collected the data and performed the statistical and econometric work, wrote the appendix and adapted the text to the sustainability template.

Funding: We gratefully acknowledge financial support from FCT and FEDER/COMPETE, through grant UID/ECO/04007/2013 (POCI-01-0145-FEDER-007659).

Acknowledgments: We thank four referees for important comments and suggestions which contributed to improve the paper. In particular, we want to thank the suggestions made by one of the referees to include Section 5 in the paper. The usual disclaimer applies.

Conflicts of Interest: The authors declare no conflict of interest. 


\section{Appendix A. Alternative Results: Secondary Schooling}

Table A1. Schooling, income, and energy intensity: alternative results to secondary schooling.

\begin{tabular}{|c|c|c|c|}
\hline & $\begin{array}{c}\text { (1) } \\
\text { Without School-Enlarged Sample }\end{array}$ & $\begin{array}{c}\text { (2) } \\
\text { Without School-Same Sample }\end{array}$ & $\begin{array}{c}\text { (3) } \\
\text { With School }\end{array}$ \\
\hline Income per Capita ${ }_{t-1}$ & $\begin{array}{c}-0.0001 \\
(0.313)\end{array}$ & $\begin{array}{c}-0.0001 \\
(0.134)\end{array}$ & $\begin{array}{c}-0.0002 \\
(0.461)\end{array}$ \\
\hline$\Delta$ Income per Capita $_{t}$ & $\begin{array}{l}-0.0007^{* * *} \\
(0.000)\end{array}$ & $\begin{array}{c}-0.0007^{* * *} \\
(0.000)\end{array}$ & $\begin{array}{c}-0.0003 \\
(0.794)\end{array}$ \\
\hline Industry Share $_{t-1}$ & $\begin{array}{l}-0.009 \\
(0.140)\end{array}$ & $\begin{array}{l}-0.004 \\
(0.488)\end{array}$ & $\begin{array}{l}0.0002 \\
(0.119)\end{array}$ \\
\hline$\Delta$ Industry Share $_{t}$ & $\begin{array}{c}0.004 \\
(0.425)\end{array}$ & $\begin{array}{c}0.02 \\
(0.663)\end{array}$ & $\begin{array}{c}-0.0004 \\
(0.103)\end{array}$ \\
\hline External Dependence $_{t-1}$ & $\begin{array}{l}-0.0000 \\
(0.174)\end{array}$ & $\begin{array}{l}-0.00001 * * \\
(0.023)\end{array}$ & $\begin{array}{l}-0.00001 * \\
(0.058)\end{array}$ \\
\hline$\Delta$ External Dependence $_{t}$ & $\begin{array}{l}0.00003^{* * * *} \\
(0.003)\end{array}$ & $\begin{array}{l}0.00003^{* * * *} \\
(0.007)\end{array}$ & $\begin{array}{l}0.00006^{* * * *} \\
(0.000)\end{array}$ \\
\hline Secondary School ${ }_{t-1}$ & - & - & $\begin{array}{c}-0.0003 \\
(0.461)\end{array}$ \\
\hline$\Delta$ Secondary School $_{t}$ & - & - & $\begin{array}{c}-0.0003 \\
(0.794) \\
\end{array}$ \\
\hline Error Correction Coefficient $E_{i t-1}$ & $\begin{array}{l}-0.353^{* * *} \\
(0.000)\end{array}$ & $\begin{array}{l}-0.367^{* * *} \\
(0.000)\end{array}$ & $\begin{array}{l}-0.363^{* * * *} \\
(0.002)\end{array}$ \\
\hline N Observ. & 1631 & 1266 & 1266 \\
\hline Avr. N Obs. & 31.4 & 32.5 & 32.5 \\
\hline Min-Max & $26-35$ & $31-35$ & $31-35$ \\
\hline Number Countries & 52 & 39 & 39 \\
\hline Wald & $152.22 * * *$ & $67.41^{* * *}$ & $67.41^{* * *}$ \\
\hline CD-test (res) & $\begin{array}{l}2.98^{* * *} \\
(0.003)\end{array}$ & $\begin{array}{l}2.54 * * \\
(0.011)\end{array}$ & $\begin{array}{c}0.71 \\
(0.480)\end{array}$ \\
\hline Stat-test (res) & rejects I(1) & rejects $\mathrm{I}(1)$ & rejects I(1) \\
\hline
\end{tabular}

Note: The dependent variable is energy intensity (energy consumption/GDP). Values in parentheses below coefficients are $p$-values from robust (clustered) standard errors. The regressions include two lags of lagged differences of cross-section averages. Level of significance: ${ }^{* * *}$ for $p$-value $<0.01$; ${ }^{* *}$ for $p$-value $<0.05$; * for $p$-value $<0.1$. The Wald test is a joint significance test for the regressors. CD-test is a Pesaran (2004) cross-section dependence test on the null value of cross-section independence done on the residuals from the regression ( $p$-value presented in parentheses). The Stat-test is the Pesaran (2007) unit root test made on the residuals. This test used four lags and rejected I(1) meaning that in all lags, the test of the unit root rejects with and without a trend. The list of countries were used in regressions is available upon request.

\section{Appendix B. Sample Coverage: Countries and Years}

\section{Appendix B.1. Column 1}

Argentina (1950-1980); Australia (1950-1980); Belgium (1950-1980); Bolivia (1950-2006); Brazil (1950-2008); Bulgaria (1950-2009); Burma (1952-1980); Canada (1950-2009); Chile (1950-2009); China PR(1959-2008); Colombia (1950-2008); Costa Rica (1953-2008); Czechoslovakia (1950-1980); Denmark (1950-2008); Ecuador (1950-2008); El Salvador (1955-2008); Finland (1957-2008); France (1950-2008); German DR (1953-1980); German FR (1953-1980); Greece (1950-2008); Guatemala (1950-2008); Hungary (1950-2008); India (1951-1980); Indonesia (1953-2008); Iran (1950-2007); Ireland (1950-1980); Italy (1950-2008); Japan (1956-2008); Korea, South (1952-2008); Liberia (1950-1980); Mexico (1950-2008); Netherlands (1950-1980); Nicaragua (1950-2008); Norway (1950-2008); Pakistan (1951-2008); Peru (1950-1980); Philippines (1950-2008); Poland (1957-2008); Portugal (1950-2008); South Africa (1950-2008); Spain (1950-2008); 
Sweden (1950-1980); Switzerland (1950-1980); Thailand (1957-2008); Turkey (1950-1980); USSR (Russia) (1950-1980); United Kingdom (1950-2008); United States (1950-2008); Uruguay (1950-2008); Venezuela (1950-2008); Yugoslavia (1955-1980).

Appendix B.2. Column 2

Argentina (1950-1980); Australia (1950-1980); Belgium (1950-1980); Bolivia (1950-2006); Brazil (1950-2008); Bulgaria (1950-2009); Burma (1952-1980); Canada (1950-2009); Chile (1950-2009); China PR(1959-2008); Colombia (1950-2008); Costa Rica (1953-2008); Czechoslovakia (1950-1980); Denmark (1950-2008); Ecuador (1950-2008); El Salvador (1955-2008); Finland (1957-2008); France (1950-2008); German DR (1953-1980); German FR (1953-1980); Greece (1950-2008); Guatemala (1950-2008); Hungary (1950-2008); India (1951-1980); Indonesia (1953-2008); Iran (1950-2007); Ireland (1950-1980); Italy (1950-2008); Japan (1956-2008); Korea, South (1952-2008); Liberia (1950-1980); Mexico (1950-2008); Netherlands (1950-1980); Nicaragua (1950-2008); Norway (1950-2008); Pakistan (1951-2008); Peru (1950-1980); Philippines (1950-2008); Poland (1957-2008); Portugal (1950-2008); South Africa (1950-2008); Spain (1950-2008); Sweden (1950-1980); Switzerland (1950-1980); Thailand (1957-2008); Turkey (1950-1980); USSR (Russia) (1950-1980); United Kingdom (1950-2008); United States (1950-2008); Uruguay (1950-2008); Venezuela (1950-2008); Yugoslavia (1955-1980).

Appendix B.3. Column 3

Argentina (1950-1980); Australia (1950-1980); Belgium (1950-1980); Bolivia (1950-2006); Brazil (1950-2008); Bulgaria (1950-2009); Canada (1950-2008); Chile (1950-2009); Colombia (1950-2008); Costa Rica (1953-2008); Czechoslovakia (1950-1980); Ecuador (1950-2007); France (1950-2008); Greece (1950-2007); Guatemala (1950-2008); Hungary (1950-2008); Iran (1950-2007); Ireland (1950-1980); Italy (1950-2008); Korea, South (1952-2008); Liberia (1950-1980); Mexico (1950-2008); Netherlands (1950-1980); Nicaragua (1950-2008); Norway (1950-2008); Pakistan (1951-2008); Peru (1950-1980); Philippines (1950-2008); Portugal (1950-2008); South Africa (1950-2008); Spain (1950-2008); Sweden (1950-1980); Switzerland (1950-1980); Turkey (1950-1980); USSR (Russia) (1950-1980); United Kingdom (1950-2008); United States (1950-2008); Uruguay (1950-2008); Venezuela (1950-2008).

\section{References}

1. Csereklyei, Z.M.; Rubio-Varas, D.; Stern, D. Energy and economic growth: The stylized facts. Energy J. 2016, 37, 223-255. [CrossRef]

2. Metcalf, G. An Empirical Analysis of Energy Intensity and Its Determinants at the State Level. Energy J. 2008, 29, 1-26. [CrossRef]

3. Sahu, S.; Narayana, K. Determinants of Energy Intensity in Indian Manufacturing: An Econometric Analysis. Eurasia. J. Bus. Econo. 2011, 4, 13-30.

4. Wu, Y. Energy intensity and its determinants in China's regional economies. Energy Policy 2012, 41, 703-711. [CrossRef]

5. Mulder, P.; Groot, L.; Pfeiffer, B. Dynamics and determinants of energy intensity in the service sector: A cross-country analysis, 1980-2005. Ecol. Econ. 2014, 100, 1-15. [CrossRef]

6. Chang, S. Effects of financial developments and income on energy consumption. Int. Rev. Econ. Financ. 2015, 35, 28-44. [CrossRef]

7. UNESCO. Division of Science, Technical and Environmental Education; Environmental Education Series; UNESCO: Paris, France, 1986.

8. Hoango, T.; Kato, T. Measuring the effect of environmental education for sustainable development at elementary schools: A case study in Da Nang city, Vietnam. Sustain. Environ. Res. 2016, 26, $274-286$. [CrossRef] 
9. Alaydin, E.; Demirel, G.; Altin, S.; Altin, A. Environmental Knowledge of Primary School Students: Zonguldak (Turkey) Example. Proc. Soc. Behav. 2013, 141, 11501155. [CrossRef]

10. Yeh, S.; Huang, J.; Yu, H. Analysis of Energy Literacy and Misconceptions of Junior High Students in Taiwan. Sustainability 2017, 9, 423. [CrossRef]

11. Ntanos, S.; Kyriakopoulos, G.; Arabatzis, G.; Palios, V.; Chalikias, M. Environmental Behavior of Secondary Education Students: A Case Study at Central Greece. Sustainability 2018, 10, 1663. [CrossRef]

12. Lefkeli, S.; Manolas, E.; Ioannou, K.; Tsantopoulos, G. Socio-Cultural Impact of Energy Saving: Studying the Behaviour of Elementary School Students in Greece. Sustainability 2018, 10, 737. [CrossRef]

13. Van den Branden, K. Sustainable Education: Exploiting Students Energy for Learning as a Renewable Resource. Sustainability 2015, 7, 5471-5487. [CrossRef]

14. Sequeira, T.; Santos, M. Renewable energy and politics: A systematic review and new evidence. J. Clean. Prod. 2018, 192, 553-568. [CrossRef]

15. Gaede, J.; Rowlands, I. Visualizing social acceptance research: A bibliometric review of the social acceptance literature for energy technology and fuels. Energy Res. Soc. Sci. 2018, 40, 142-158. [CrossRef]

16. Kongsamut, P.; Rebelo, S.; Xie, D. Beyond Balanced Growth. Rev. Econ. Stud. 2001, 68, 869-882. [CrossRef]

17. Steger, T. Economic growth with subsistence consumption. J. Dev. Econ. 2000, 62, 343-361. [CrossRef]

18. Acemoglu, D. Introduction to Modern Economic Growth; Princeton University Press: Princeton, NJ, USA, 2009.

19. Viscusi, W.; Evans, W. Utility Functions That Depend on Health Status: Estimates and Economic Implications. Am. Econ. Rev. 1990, 80, 352-374.

20. Lazear, E. Education: Consumption or Production; NBER Working-Paper Series 104; University of Chicago Press: Chicago, IL, USA, 1975.

21. Galor, O. From Stagnation to Growth: Unified Growth Theory. In Handbook of Economic Growth, 1st ed.; Aghion, P., Durlauf, S., Eds.; Elsevier: Amsterdam, The Netherlands, 2005; Volume 1, p. 1.

22. Arnold, L. Growth, Welfare and Trade in an Integrated Model of Human-capital Accumulation and Research. J. Macroecon. 1998, 20, 81-105. [CrossRef]

23. Gómez, M.; Sequeira, T. Should the US increases subsidies to R\&D? Lessons from an Endogenous Growth Theory. Oxf. Econ. Pap. 2014, 66, 254-282. [CrossRef]

24. Horbach, J.; Rammer, C.; Rennings, K. Determinants of eco-innovations by type of environmental impact The role of regulatory push/pull, technology push and market pull. Ecol. Econ. 2012, 78, 112-122. [CrossRef]

25. World Energy Council. Energy Efficiency Technologies: Overview Report. Available online: https://www. worldenergy.org/publications/ (accessed on 20 May 2016).

26. Reis, A.B. Endogenous growth and the possibility of eliminating pollution. J. Environ. Econ. Manag. 2001, 42, 360-373. [CrossRef]

27. Ferreira-Lopes, A.; Sequeira, T.; Roseta-Palma, C. On The Effect of Technological Progress on Pollution: An Overlooked Distortion in Endogenous Growth. Oxf. Econ. Pap. 2013, 65, 394-416. [CrossRef]

28. Hordeski, M. New Technologies for Energy Efficiency; The Fairmont Press and Marcel Dekker Inc.: Lilburn, GA, USA, 2002.

29. Liobikienè, G.; Butkus, M. Environmental Kuznets Curve of greenhouse gas emissions including technological progress and substitution effects. Energy 2017, 135, 237-248. [CrossRef]

30. Stern, D. The Rise and Fall of the Environmental Kuznets Curve. World Dev. 2004, 32, 1419-1439. [CrossRef]

31. Winter, I. Energy Concepts in Primary Education. In Energy Resources in Science Education: A Volume in Science and Technology Education and Future Human Needs, 1st ed.; Kirwan, D., Ed.; Pergamon Press: Oxford, UK, 2005; pp. 35-37, ISBN 978-0-08-033950-4.

32. Banks, A.S.; Wilson, K. Cross-National Time-Series Data Archive; Databanks International: Jerusalem, Israel, 2015.

33. Medlock, K., III. Energy Demand Theory. In International Handbook of Economics of Energy; Evans, J., Hunt, L., Eds.; Edward Elgar Publishing Group: Cheltenham, UK, 2009.

34. European Commission. Member States Energy Dependence: An Indicator-Based Assessment; Occasional Papers 145; European Commission: Brussels, Belgium, 2015.

35. Nelson, C.; Plosser, C. Trends and random walks in macroeconomic time series: some evidence and implications. J. Monetary Econ. 1982, 10, 139-162. [CrossRef]

36. Rapach, D. Are real GDP levels nonstationary? Evidence from panel data tests. South Econ. J. 2002, 68, 473-495. [CrossRef] 
37. Eberhardt, M.; Teal, F. Econometrics for Grumblers: A New Look at the Literature on Cross-Country Growth Empirics. J. Econ. Surv. 2011, 25, 109-155. [CrossRef]

38. Pesaran, M. General Diagnostic Tests for Cross Section Dependence in Panels; University of Cambridge: Cambridge, UK, 2004.

39. Pesaran, M. Testing Weak Cross-Sectional Dependence in Large Panels. Econom. Rev. 2015, 34, $1089-1117$. [CrossRef]

40. Pesaran, M. Estimation and inference in large heterogeneous panels with a multifactor error structure. Econometrica 2006, 74, 967-1012. [CrossRef]

41. Sequeira, T.; Santos, M. Does country-risk influence electricity production worldwide? J. Policy Model. 2018. [CrossRef]

42. Banerjee, A.; Carrion-i-Silvestre, J. Testing for Panel Cointegration using Common Correlated Effects Estimators. J. Time Ser. Anal. 2017, 38, 610-1636. [CrossRef]

43. Chudik, A.; Pesaran, M. Common Correlated Effects Estimation of Heterogeneous Dynamic Panel Data Models with Weakly Exogenous Regressors. J. Econom. 2015, 188, 393-420. [CrossRef]

44. Lee, C.; Chang, C. The impact of energy consumption on economic growth: Evidence from linear and nonlinear models in Taiwan. Energy 2007, 32, 2282-2294. [CrossRef]

45. Eberhardt, M.; Prebistero, A. Public debt and growth: Heterogeneity and non-linearity.J. Int. Econ. 2015, 97, 45-58. [CrossRef]

46. Everaert, G.; Groote, T. Common Correlated Effects Estimation of Dynamic Panels with Cross-Sectional Dependence. Econom. Rev. 2015, 35, 428-463. [CrossRef]

47. Arellano, M.; Bond, S. Some tests of specification for panel data: Monte Carlo evidence and an application to employment equations. Rev. Econ. Stud. 1991, 58, 277-297. [CrossRef]

48. McGue, M.; Osler, M.; Christensen, K. Causal Inference and Observational Research: The Utility of Twins. Perspect. Psychol. Sci. 2010, 5, 546-556. [CrossRef] [PubMed]

49. Pesaran, M. A Simple panel unit root test in the presence of cross-section dependence. J. Appl. Econom. 2007, 22, 265-312. [CrossRef]

(C) 2018 by the authors. Licensee MDPI, Basel, Switzerland. This article is an open access article distributed under the terms and conditions of the Creative Commons Attribution (CC BY) license (http://creativecommons.org/licenses/by/4.0/). 